\title{
The influence of prognostic factors and adjuvant chemoradiation on survival after pancreaticoduodenectomy for ampullary carcinoma.
}

Timothy N Showalter

Thomas Jefferson University

Tingting Zhan

Thomas Jefferson University

P Rani Anne

Thomas Jefferson University

Inna Chervoneva

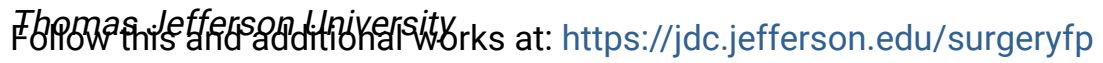

WhaP Bitioesellirgery Commons

Theras is feferso Uwiversitw access to this document benefits you

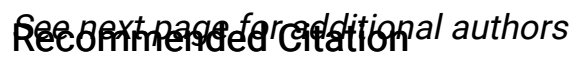

Showalter, Timothy N; Zhan, Tingting; Anne, P Rani; Chervoneva, Inna; Mitchell, Edith P; Yeo, Charles J; Rosato, Ernest L; Kennedy, Eugene P; and Berger, Adam C, "The influence of prognostic factors and adjuvant chemoradiation on survival after pancreaticoduodenectomy for ampullary carcinoma." (2012). Department of Surgery Faculty Papers. Paper 42.

https://jdc.jefferson.edu/surgeryfp/42

This Article is brought to you for free and open access by the Jefferson Digital Commons. The Jefferson Digital Commons is a service of Thomas Jefferson University's Center for Teaching and Learning (CTL). The Commons is a showcase for Jefferson books and journals, peer-reviewed scholarly publications, unique historical collections from the University archives, and teaching tools. The Jefferson Digital Commons allows researchers and interested readers anywhere in the world to learn about and keep up to date with Jefferson scholarship. This article has been accepted for inclusion in Department of Surgery Faculty Papers by an authorized administrator of the Jefferson Digital Commons. For more information, please contact: JeffersonDigitalCommons@jefferson.edu. 
Authors

Timothy N Showalter, Tingting Zhan, P Rani Anne, Inna Chervoneva, Edith P Mitchell, Charles J Yeo, Ernest L Rosato, Eugene P Kennedy, and Adam C Berger 


\title{
As submitted to: \\ Journal of Gastrointestinal Surgery
}

\author{
And Later published as:
}

\section{The influence of prognostic factors and adjuvant}

\author{
chemoradiation on survival after
}

pancreaticoduodenectomy for ampullary carcinoma

\author{
Volume 15, Issue 8, August 2011, Pages 1411-1416
}

\section{DOI: 10.1007/s11605-011-1518-6}

Timothy N. Showalter ${ }^{1}$, Tingting Zhan ${ }^{2}$, P. Rani Anne ${ }^{1}$, Inna Chervoneva ${ }^{2}$, Edith P. Mitchell $^{3}$, Charles J. Yeo ${ }^{4}$, Ernest L. Rosato ${ }^{4}$, Eugene P. Kennedy ${ }^{4}$, Adam C. Berger ${ }^{4}$

${ }^{1}$ Department of Radiation Oncology, Jefferson Medical College of Thomas Jefferson University, Kimmel Cancer Center, Philadelphia, PA ${ }^{2}$ Division of Biostatistics, Department of Pharmacology and Experimental Therapeutics, Thomas Jefferson University, Philadelphia, PA; ${ }^{3}$ Department of Medical Oncology, Jefferson Medical 
College of Thomas Jefferson University, Kimmel Cancer Center, Philadelphia, PA $;^{4}$ Department of Surgery, Jefferson Medical College of Thomas Jefferson University, and the Jefferson Pancreas, Biliary and Related Cancer Center, Philadelphia, PA

Correspondence: Adam C. Berger; 1100 Walnut Street, MOB, Suite 500; Philadelphia, PA 19147; phone—(215) 955-1622; fax—(215) 923-8222; email: adam.berger@jefferson.edu

This work was originally presented in poster form at the Fifth ASCO GI Symposium, January 2009 (Orlando, FL).

Running Title: Ampullary cancer prognostic factors

Key Words: ampullary cancer, adjuvant therapy, ampulla of Vater, adenocarcinoma 


\begin{abstract}
INTRODUCTION: The prognosis after pancreaticoduodenectomy (PD) for ampullary carcinoma $(\mathrm{AC})$ is superior to that of pancreatic cancer. Decisions regarding adjuvant therapy are influenced by factors such as nodal status, stage, and grade, but the influence of these individual variables on survival is unclear.
\end{abstract}

METHODS: A prospective tumor registry database was queried to identify patients who underwent PD for AC at Thomas Jefferson University between 1/1997 and 4/2009. The study was conducted with the approval of the institutional review board. Data were collected through review of hospital and departmental charts. Overall survival (OS) was analyzed using univariate and multivariate Cox proportional hazard models. The proportional hazard assumption was verified for the overall model and individual covariates.

RESULTS: A total of 61 patients underwent PD for AC at our institution. There were 5 peri-operative deaths $(8.2 \%)$. Mean age was 70 years (62\% male). Median survival time (MST) was 50 months for all patients. Only primary tumor stage, T1/T2 versus T3/T4 (American Joint Committee on Cancer Staging Version 6), was associated with OS in univariate analyses $(\mathrm{p}=0.003)$. The association of nodal status with OS was borderlinesignificant $(\mathrm{p}=0.08)$, with the MST being 84 months for node-negative and 17 months for node-positive patients. The remaining covariates were not predictors of OS. In the multivariate analysis, only primary tumor stage (HR 5.1, p < 0.001) and age (HR 1.04, $\mathrm{p}=0.06$ ), but not nodal status or adjuvant therapy, were associated with overall survival. 
CONCLUSIONS: Advanced primary tumor stage and age were associated with inferior OS after PD for AC. Adjuvant therapy did not impact survival. Patients with advanced tumor stage should be considered for clinical trials of adjuvant therapy after PD with novel compounds and optimized radiation therapy strategies. 


\section{INTRODUCTION}

Carcinoma of the ampulla of Vater is a relatively uncommon malignancy and accounts for approximately 10 to $20 \%$ of pancreaticoduodenectomies (PDs) performed for periampullary cancers ${ }^{1-3}$. Prognosis after PD for ampullary carcinoma (AC) is superior to that of pancreatic cancer (PC), with higher rates of complete surgical resection, lower recurrence rates, and longer survival ${ }^{1}$. Published 5-year overall survival (OS) rates for ampullary carcinoma range from $38 \%$ to $68 \%{ }^{1-7}$. There are less published data available for $\mathrm{AC}$ than for $\mathrm{PC}$ to assist with decisions regarding adjuvant therapy. The only randomized, prospective trial of adjuvant radiotherapy and concurrent chemotherapy to include patients with AC was that reported by the European Organisation for Research and Treatment of Cancer (EORTC) ${ }^{8}$. This study randomized patients with cancers of the pancreatic head or the periampullary region, defined as the distal common bile duct, ampulla of Vater, or duodenum, to the addition of adjuvant chemoradiotherapy (CRT) after surgery versus surgery alone. The study results showed that CRT did not improve OS rates in this trial. Results of this study are controversial, but they do not lend support for adjuvant therapy for either PC or AC ${ }^{8}$. Retrospective, single-institution studies have suggested conflicting results for the role of CRT in AC; most notably that adjuvant CRT extends survival either only in patients with involved lymph nodes, ${ }^{5}$ or only in patients with advanced tumor stage. ${ }^{9}$

Previous retrospective studies have identified clinical and pathologic factors that predict poorer outcome after $\mathrm{PD}$ for $\mathrm{AC}$, in an effort to identify high-risk patients who may benefit most from adjuvant therapy. Reported prognostic factors include specimen lymph node involvement, poor histologic grade, positive resection margins, and higher 
tumor stage (T3/T4 versus T1/T2). ${ }^{1,3,5,7,10,11}$ This analysis of outcomes for patients treated for AC at Thomas Jefferson University Hospital was performed to evaluate the associations of reported prognostic factors with overall survival after PD, and to assess the impact of adjuvant CRT on overall survival.

\section{METHODS}

A prospective tumor registry database was queried to identify patients who underwent PD for AC at Thomas Jefferson University between 1/1997 and 4/2009. The study was conducted with the approval of the institutional review board. Data were collected through chart review and included age, gender, perioperative complications, margin status, stage, adjuvant therapy, survival, and recurrence. Tumor staging was performed according to the $7^{\text {th }}$ edition of the American Joint Committee on Cancer Staging Manual (Tables 1 and 2). During the study period, decisions regarding adjuvant therapy were made by the treating physicians without a consistent policy, but the tendency was to reserve CRT for those patients with high-risk features such as positive nodes.

Time to recurrence (TTR) was estimated from the date of surgical resection, and the location of first recurrence was recorded. The recurrence rate for node-positive tumors was compared to node-negative tumors using Fisher exact test. Overall survival (OS) was estimated from the date of surgical resection. The overall survival was analyzed using univariate and multivariate Cox proportional hazard models and reported including 95\% confidence intervals (CI). For statistical analysis, tumor (T) stage was dichotomized as "low" (T1/T2) versus "high" (T3/T4), and the histological grade was 
dichotomized as "low" (well- and moderately-differentiated) versus "high" (poorlydifferentiated). Factors included in the multivariate analysis were age, primary tumor stage (T1/T2 vs. T3/T4), grade, nodal status (N0 vs. N1), adjuvant CRT and adjuvant chemotherapy. The final multivariate Cox model was selected using the Akaike Information Criterion. ${ }^{12}$ The proportional hazard assumption was verified for the overall model and for the individual covariates. Data were analyzed in R 2.10 (R Foundation for Statistical Computing, http://www.R-project.org).

\section{RESULTS}

Sixty-one patients were identified who underwent PD for AC at our institution between $1 / 1997$ and 4/2009. There were 5 peri-operative deaths (8.2\%), with the causes being pulmonary embolism in 1 patient, respiratory failure in 1 patient, and cardiac events in 3 patients. Median follow-up of surviving patients was 22.4 months. Average age was 70 years, and $62 \%$ were male. Negative microscopic margins (R0) were achieved in 58 patients $(95 \%)$. Positive margins $(n=3)$ were identified at the uncinate $(\mathrm{n}=1)$ and circumferential $(\mathrm{n}=2)$ margins of resection. Sixteen patients $(29 \%)$ received adjuvant RT, which was delivered in combination with concurrent 5-fluorouracil (5-FU) or capecitabine. RT doses used were 45-52.2 Gy, with median of 50.4 Gy. Five patients treated with adjuvant CRT also received intraoperative RT boost (median dose, $15 \mathrm{~Gy}$ ). A total of 25 patients received additional adjuvant chemotherapy after CRT, including gemcitabine or 5-FU (Table 3).

\section{Recurrence}


Tumor recurrence was observed in 20 patients $(36 \%)$ at a median of 10.5 months after surgery. Distant metastases were present at the time of first recurrence in 13 patients, including liver in 11 patients and lungs in 3 patients. Regional lymph nodes were involved at time of first recurrence for 6 patients. Initial recurrence of AC was noted to be locoregional-only, without any distant dissemination, for 4 patients. Three of $20(15 \%)$ node-negative patients developed recurrence, which occurred in regional lymph nodes $(n=1)$ and liver $(n=2)$. Seventeen of $41(41 \%)$ node-positive patients developed recurrence, which occurred in regional lymph nodes $(n=5)$, liver $(n=9)$, and lungs $(n=3)$. The recurrence rate for node-negative patients was significantly lower than for nodepositive patients $(\mathrm{p}=0.03)$.

Survival

The median survival time (MST) was 50 months for all patients, with 2-year and 5-year survival rates of 64\% (95\% CI, 52\%-80\%) and 44\% (95\% CI, 30\%-65\%), respectively (Figure 1). The 2-year and 5-year survival rates were 85\% (95\% CI, 73\%$100 \%)$, and $65 \%(95 \% \mathrm{CI}, 46 \%-92 \%)$, respectively, for T1/T2 tumors $(\mathrm{n}=33)$, versus $39 \%(95 \% \mathrm{CI}, 23 \%-67 \%)$, and 20\% (95\% CI, 6\%-60\%) for T3/T4 tumors $(\mathrm{n}=28)(\mathrm{p}=$ 0.003). The MST was not reached for the T1/T2 group, and was 16 months for the T3/T4 group (Figure 2). The MST, 2-year survival and 5-year survival rates were 84 months, $85 \%$ (95\% CI, 71\%-100\%), and 60\% (95\% CI, 38\%-94\%), respectively, for nodenegative tumors, versus 17 months, 50\% (95\% CI, 34\%-72\%) and 33\% (95\% CI, 17\%$65 \%$ ) for node-positive tumors (Figure 3$)(\mathrm{p}=0.081)$. As concerns overall survival, by univariate analyses, neither tumor grade, age, gender, adjuvant chemotherapy, nor adjuvant CRT were associated with overall survival. However, tumor stage was 
associated with overall survival $(\mathrm{p}=0.003)$, and nodal status demonstrated a borderlinesignificant association $(\mathrm{p}=0.08)$ (Table 4$)$. In multivariate analysis, only tumor stage (T1/2 vs. T3/4) was significantly associated with OS, with HR 5.08 (95\% CI 1.95-13.25, $p<0.001)$, and age had borderline-significant association, with HR 1.04 (95\% CI 1.00$1.08, p=0.06$ ). Tumor grade, nodal status, adjuvant CRT, and adjuvant chemotherapy were not significant independent predictors of survival.

\section{DISCUSSION}

In the current study, tumor stage and age were associated with OS, and the MST was not reached for T1/T2 tumors. A similar association between tumor stage and OS has been reported in previous series, including recent reports from M.D. Anderson Cancer Center $^{9}$ and Johns Hopkins Hospital ${ }^{13}$ that showed inferior OS for T3 and T4 AC tumors compared to T1 and T2 tumors. The median survival seen in the current series compares favorably with that found at Hopkins (50 versus 36 months). Additionally, 5year survival rates were similar for lymph node negative $(60 \%)$ and T1/T2 tumors $(65 \%)$ to those seen in the group reported by M.D. Anderson. The significant association between age and OS differs from the findings of other investigators, including Krishnan et al. and Yeh et al., who found that advanced age was not associated with inferior survival after PD for AC. ${ }^{9,14}$ Conclusions regarding the influence of age on OS for AC are limited due to the relatively small numbers of patients in these series. Lymph node

involvement, which has been shown to be associated with OS in multiple series, ${ }^{1,3,5,15,16}$ 
was a borderline-significant predictor of OS in the current series, with median survival time of 84 months for $\mathrm{N} 0$ patients versus 17 months for $\mathrm{N} 1$ patients. In our experience, lymph node-negative AC patients had lower rates of recurrence and better overall survival than patients with nodal involvement. The current study is limited by its retrospective design, with non-randomized treatment allocation, as well as the relatively small number of patients treated for this uncommon cancer diagnosis. It is possible that a significant association between nodal status and OS would be revealed with a larger population of $\mathrm{AC}$ patients.

The role of adjuvant CRT in the management of AC is not clear. In the present study, adjuvant CRT did not influence OS. Interpretation of the observed lack of effect of CRT on OS is limited by the small number of patients in this study; less than $50 \%$ of patients in our series received any adjuvant therapy. The EORTC prospective trial of CRT for periampullary cancers included 92 patients with AC. In this EORTC trial, which comprised the only prospective, randomized data for CRT in AC, CRT did not improve OS, with 2 year survival rate of $70 \%$ versus $64 \%$ with and without CRT, respectively. ${ }^{8}$ Similarly, Zhou and colleagues, in their 2009 report of 111 AC patients treated at the Johns Hopkins Hospital, also observed no clinical benefit from CRT. ${ }^{13}$ A recent report by Krishnan et al., from MD Anderson, observed that CRT improved survival for AC patients with T3/T4 tumors, but not for patients with involved lymph nodes. ${ }^{9}$ On the other hand, adjuvant CRT has been reported by other authors to improve survival for AC patients with positive lymph nodes. ${ }^{5,17}$ Future studies that include a larger number of patients may provide further insight into which subsets of AC patients will benefit from adjuvant CRT. 
Previous reports have focused on the identification of high-risk factors that predict for higher rates of recurrence, using either models of multiple pathologic factors or lymph node-based parameters, such as number of positive nodes and lymph node ratio 10,15,16. Given the influence of lymph node status on rates of recurrence and survival after PD for AC, it seems reasonable to consider closely these lymph node parameters when evaluating prognosis. Recent data have demonstrated that primary tumor stage and nodal status are correlated in AC, with increased risk of nodal metastasis for T3/4 (71.1-77.3\%) versus T1/2 (28.0-50.9\%) tumors. ${ }^{18}$ It is unclear whether these prognostic approaches may be used as the basis for decisions regarding adjuvant CRT for AC patients. Although the current analysis suggests that tumor stage, age, and lymph node involvement are associated with overall survival, the addition of adjuvant CRT after PD did not improve survival. Since they are associated with inferior survival after PD, these adverse factors should be considered when developing novel strategies for adjuvant therapy for AC patients.

In conclusion, only primary tumor stage, and not nodal status or the use of adjuvant CRT, was associated with OS after PC for AC. Patients with advanced primary tumor stage should be considered for clinical trials of adjuvant therapy with novel compounds and optimized RT strategies, while observation following surgical resection may be considered for patients with T1/2 and node-negative AC. 


\section{REFERENCES}

1. Talamini MA, Moesinger RC, Pitt HA, et al: Adenocarcinoma of the ampulla of Vater. A 28-year experience. Ann Surg 225:590-600, 1997

2. Duffy JP, Hines OJ, Liu JH, et al: Improved survival for adenocarcinoma of the ampulla of Vater: fifty-five consecutive resections. Arch Surg 138:941-950, 2003

3. Brown KM, Tompkins AJ, Yong S, et al: Pancreaticoduodenectomy is curative in the majority of patients with node-negative ampullary cancer. Arch Surg 140:529-533, 2005

4. Allema JH, Reinders ME, van Gulik TM, et al: Results of pancreaticoduodenectomy for ampullary carcinoma and analysis of prognostic factors for survival. Surgery 117:247-253, 1995

5. Bhatia S, Miller RC, Haddock MC, et al: Adjuvant therapy for ampullary carcinomas: the Mayo Clinic experience. Int $\mathrm{J}$ Radiat Oncol Biol Phys 66:514-519, 2006

6. O'Connell JB, Maggard MA, Manunga J, Jr., et al: Survival after resection of ampullary carcinoma: a national population-based study. Ann Surg Oncol 15:1820-1827, 2008

7. Qiao Q-I, Zhao Y-g, Ye M-I, et al: Carcinoma of the ampulla of Vater: factors influencing long-term survival of 127 patients with resection. World J Surg 31:137-143, 2007

8. Klinkenbijl JH, Jeekel J, Sahmoud T, et al: Adjuvant radiotherapy and 5 -fluorouracil after curative resection of cancer of the pancreas and periampullary region: Phase III trial of the EORTC Gastrointestinal Tract Cancer Cooperative Group. Ann Surg 230:776-782, 1999

9. Krishnan S, Rana V, Evans DB, et al: Role of adjvuant chemoradiation therapy in adenocarcinomas of the ampulla of Vater. Int $\mathrm{J}$ Radiat Oncol Biol Phys 70:735-743, 2008

10. Willett CG, Warshaw AL, Convery K, et al: Patterns of failure after pancreaticoduodenectomy for ampullary carcinoma. Surg Gynecol Obstet 176:33-38, 1993

11. Park JS, Yoon DS, Kim KS, et al: Factors influencing recurrence after curative resection for ampulla of Vater carcinoma. J Surg Oncol 95:286-290, 2007

12. Akaike $\mathrm{H}$ : A new look at the statistical model identification. IEEE Transactions on Automatic Control 19:716-723, 1974

13. Zhou J, Hsu CC, Winter JM, et al: Adjuvant chemoradiation versus surgery alone for adenocarcinoma of the ampulla of Vater. Radiother Oncol 92:244-248, 2009

14. Yeh CC, Jeng YM, Ho CM, et al: Survival after pancreaticoduodenectomy for ampullary cancer is not affected by age. World $\mathrm{J}$ Surg 34:2945-2952, 2010

15. Sakata J, Shirai Y, Wakai T, et al: Number of positive lymph nodes independently affects long-term survival after resection in patients with ampullary carcinoma. EJSO 33:346-351, 2007 
16. Falconi M, Crippa S, Dominguez I, et al: Prognostic relevance of lymph node ratio and number of resected nodes after curative resection of ampulla of Vater carcinoma. Ann Surg Oncol 15:3178-3186, 2008

17. Lee $\mathrm{JH}$, Whittington $\mathrm{R}$, Williams NN, et al: Outcome of pancreaticoduodenectomy and impact of adjuvant therapy for ampullary carcinomas. Int J Radiat Oncol Biol Phys 47:945-953, 2000

18. Winter JM, Cameron JL, Olino K, et al: Clinicopathologic analysis of ampullary neoplasms in 450 patients: implications for surgical strategy and longterm prognosis. J Gastrointest Surg 14:379-387, 2010

\section{Figure Legends}

Figure 1. Kaplan-Meier plot of overall survival (solid line) for all ampullary carcinoma patients ( $\mathrm{n}=61$ ) after pancreaticoduodenectomy, with 95\% confidence intervals (dashed line)..

Figure 2. Kaplan-Meier plot of overall survival for ampullary carcinoma patients after pancreaticoduodenectomy by primary tumor stage, comparing T1/T2 tumors (solid line, $\mathrm{n}=33)$ to $\mathrm{T} 3 / \mathrm{T} 4$ tumors (dashed line, $\mathrm{n}=28)(\mathrm{p}=0.003)$.

Figure 3. Kaplan-Meier plot of overall survival for ampullary carcinoma patients after pancreaticoduodenectomy by nodal status, comparing lymph node-negative ( $\mathrm{N} 0$, solid line, $\mathrm{n}=20)$ to lymph node-positive $(\mathrm{N} 1$, dashed line, $\mathrm{n}=41)(\mathrm{p}=0.081)$. 


\section{TABLES}

\begin{tabular}{|c|}
\hline Primary Tumor $(T)$ \\
\hline TX: Primary tumor cannot be assessed \\
\hline TO: No evidence of primary tumor \\
\hline Tis: Carcinoma in Situ \\
\hline $\begin{array}{l}\text { T1: Tumor confined in ampulla of Vater or } \\
\text { sphincter of Oddi }\end{array}$ \\
\hline T2: Tumor involves duodenal wall \\
\hline T3: Tumor invades pancreas \\
\hline $\begin{array}{l}\text { T4: Tumor invades peripancreatic soft tissue } \\
\text { or other organs }\end{array}$ \\
\hline Regional Lymph Nodes (N) \\
\hline $\begin{array}{l}\text { NX: Regional lymph nodes cannot be } \\
\text { assessed }\end{array}$ \\
\hline NO: No regional lymph node metastasis \\
\hline N1: Regional lymph node metastasis \\
\hline Distant Metastasis (M) \\
\hline MX: Distant metastasis cannot be assessed \\
\hline
\end{tabular}




\begin{tabular}{|l|}
\hline MO: No distant metastasis \\
\hline M1: Distant Metastasis \\
\hline
\end{tabular}

Table 1. Pathologic staging system for ampullary carcinoma, according to American Joint Committee on Cancer (AJCC) Version 7. Used with the permission of the AJCC, Chicago, IL. The original source for this material is the AJCC Cancer Staging Manual, Seventh Edition (2010), published by Springer Science+Business Media.

\begin{tabular}{|c|c|c|c|}
\hline \multicolumn{4}{|c|}{ Stage Grouping } \\
\hline Stage & T & N & M \\
\hline O & Tis & NO & MO \\
\hline IA & T1 & NO & MO \\
\hline IB & T2 & NO & MO \\
\hline IIA & T3 & NO & MO \\
\hline IIB & T1-3 & N1 & MO \\
\hline III & T4 & Any N & MO \\
\hline IV & Any T & Any N & M1 \\
\hline
\end{tabular}

Table 2. Stage grouping system for ampullary carcinoma, according to American Joint Committee on Cancer (AJCC) Version 7. Used with the permission of the AJCC, Chicago, IL. The original source for this material is the AJCC Cancer Staging Manual, Seventh Edition (2010), published by Springer Science+Business Media. 


\begin{tabular}{|c|c|}
\hline Factor & Value \\
\hline $\begin{array}{l}\text { Age } \\
\quad \text { Mean (Interquartile Range) }\end{array}$ & 70 years $(54,76)$ \\
\hline $\begin{array}{l}\text { Grade }[\mathrm{N}(\%)] \\
\text { Well-differentiated } \\
\text { Moderately-differentiated } \\
\text { Poorly-differentiated } \\
\text { Unknown }\end{array}$ & $\begin{array}{ll}6 & (10 \%) \\
36 & (59 \%) \\
16 & (26 \%) \\
3 & (5 \%)\end{array}$ \\
\hline $\begin{array}{l}\text { Stage }[\mathrm{N}(\%)] \\
\text { I } \\
\text { II } \\
\text { III } \\
\text { IV }\end{array}$ & $\begin{array}{ll}19 & (31 \%) \\
29 & (48 \%) \\
12 & (20 \%) \\
1 & (2 \%)\end{array}$ \\
\hline $\begin{array}{l}\text { Nodal Status }[\mathrm{N}(\%)] \\
\text { N0 } \\
\text { N1 }\end{array}$ & $\begin{array}{ll}20 & (33 \%) \\
41 & (67 \%) \\
\end{array}$ \\
\hline $\begin{array}{l}\text { Surgical Margin Status [N(\%)] } \\
\text { R0 (negative) } \\
\text { R1 (microscopic positive) } \\
\text { R2 (macroscopic positive) }\end{array}$ & $\begin{array}{ll}58 & (95 \%) \\
3 & (5 \%) \\
0 & (0 \%) \\
\end{array}$ \\
\hline $\begin{array}{l}\text { Adjuvant Chemoradiotherapy }[\mathrm{N}(\%)] \\
\text { Yes } \\
\text { No } \\
\text { Unknown }\end{array}$ & $\begin{array}{ll}16 & (26 \%) \\
36 & (59 \%) \\
9 & (15 \%)\end{array}$ \\
\hline $\begin{array}{l}\text { Adjuvant Chemotherapy }[\mathrm{N}(\%)] \\
\text { Yes } \\
\text { No } \\
\text { Unknown }\end{array}$ & $\begin{array}{ll}25 & (41 \%) \\
28 & (46 \%) \\
8 & (13 \%)\end{array}$ \\
\hline
\end{tabular}

Table 3. Age, tumor, and adjuvant therapy information for 61 ampullary carcinoma patients who were treated with pancreaticoduodenectomy. 


\begin{tabular}{|l|c|c|}
\hline \multicolumn{1}{|c|}{ Variable } & Hazard Ratio & P value \\
\hline Tumor Stage & (95\% Confidence Interval) & 0.003 \\
(T1/2 vs. T3/4) & $4.05(1.6-10.1)$ & 0.183 \\
\hline $\begin{array}{l}\text { Grade } \\
\text { (Well/Moderate vs. Poor) }\end{array}$ & $1.8(0.8-4.5)$ & 0.225 \\
\hline $\begin{array}{l}\text { Age } \\
\text { Nodal Status }\end{array}$ & $2.2(0.9-5.4)$ & 0.081 \\
(Negative vs. Positive) & $1.2(0.5-3.0)$ & 0.713 \\
\hline $\begin{array}{l}\text { Adjuvant Chemoradiotherapy } \\
\text { (Yes vs. No) }\end{array}$ & $0.6(0.2-1.4)$ & 0.741 \\
\hline $\begin{array}{l}\text { Adjuvant Chemotherapy } \\
\text { Alone } \\
\text { (Yes vs. No) }\end{array}$ & & \\
\hline Gender & & 0.235 \\
\hline Male vs. Female) & & \\
\hline Table 4. Univariate Cox prop- & & \\
\hline
\end{tabular}

Table 4. Univariate Cox proportional models of overall survival. 


\section{FIGURES}

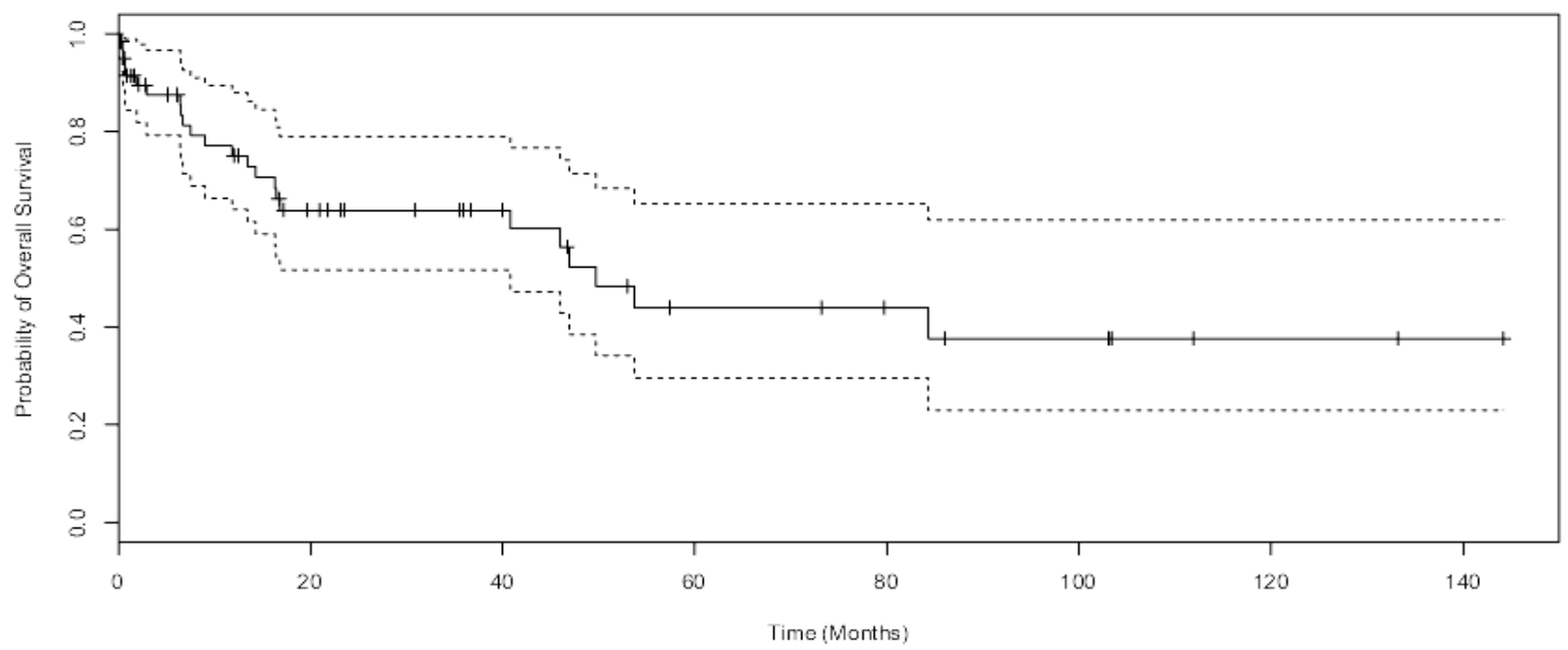

Figure 1. Kaplan-Meier plot of overall survival (solid line) for all ampullary carcinoma patients ( $\mathrm{n}=61$ ) after pancreaticoduodenectomy, with 95\% confidence intervals (dashed line).. 


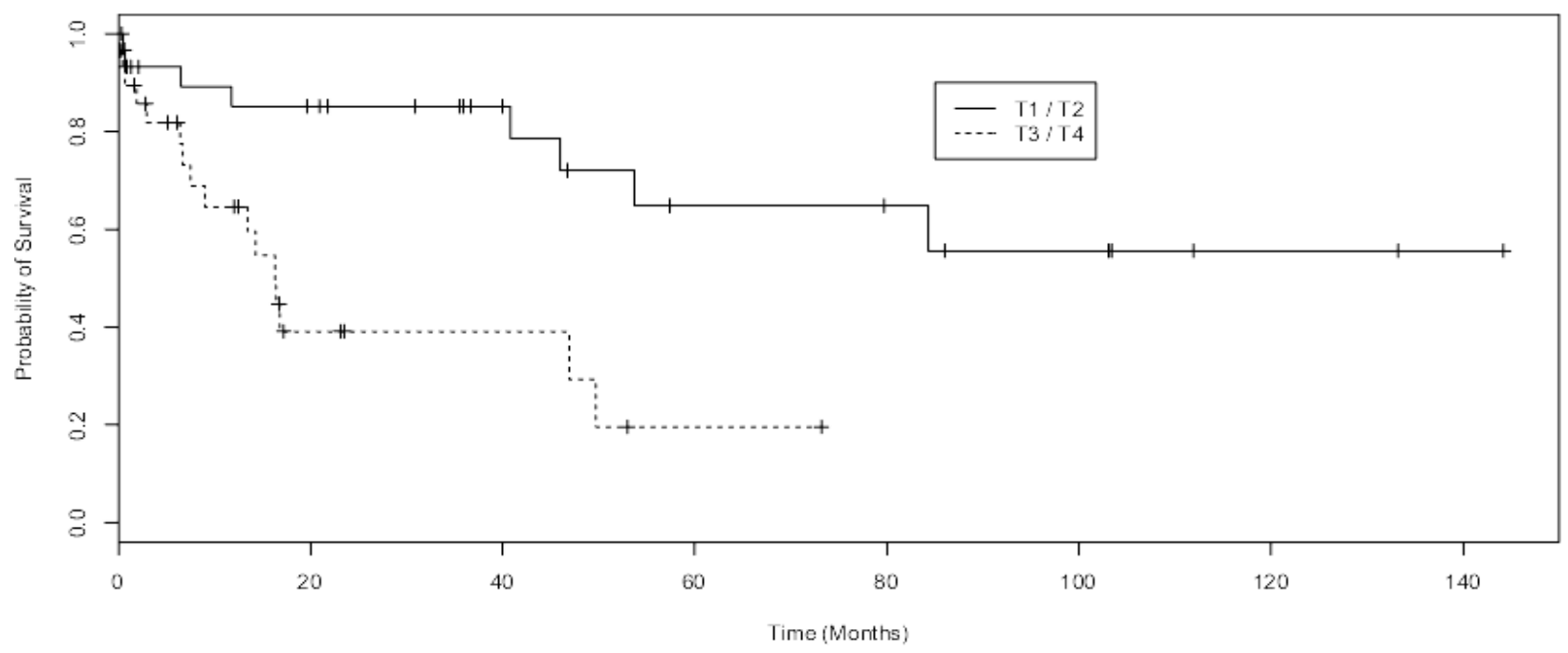

Figure 2. Kaplan-Meier plot of overall survival for ampullary carcinoma patients after pancreaticoduodenectomy by primary tumor stage, comparing T1/T2 tumors (solid line, $\mathrm{n}=33)$ to $\mathrm{T} 3 / \mathrm{T} 4$ tumors (dashed line, $\mathrm{n}=28)(\mathrm{p}=0.003)$. 


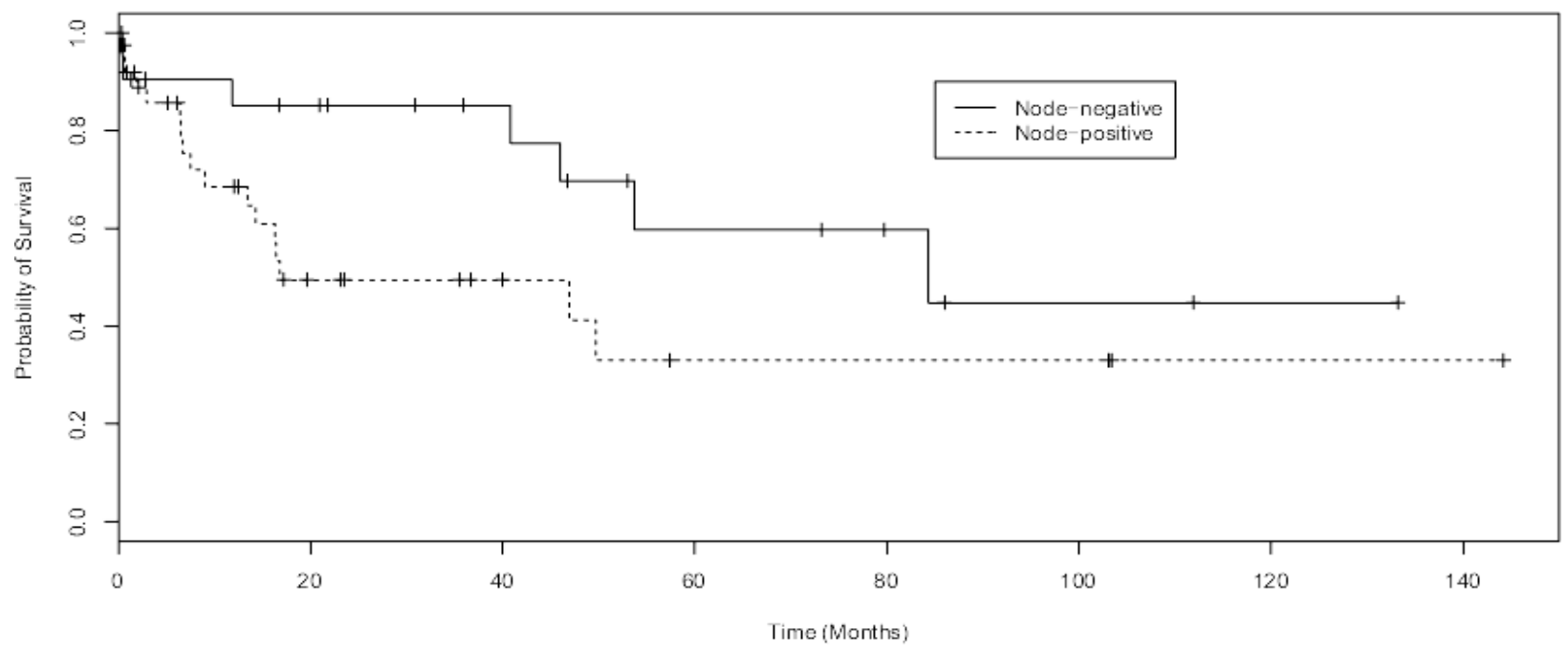

Figure 3. Kaplan-Meier plot of overall survival for ampullary carcinoma patients after pancreaticoduodenectomy by nodal status, comparing lymph node-negative (N0, solid line, $\mathrm{n}=20)$ to lymph node-positive $(\mathrm{N} 1$, dashed line, $\mathrm{n}=41)(\mathrm{p}=0.081)$. 